\title{
GNA11 brain somatic pathogenic variant in an individual with phacomatosis pigmentovascularis
}

Joseph M. Sliepka, BA, * Sarah C. McGriff, BS, BSHS, * Linda Z. Rossetti, MD, Peyman Bizargity, MD, Haley Streff, MS, CGC, Yi-Shan Lee, MD, PhD, Hongzheng Dai, PhD, Satyamaanasa Polubothu, MD, PhD, Grace Lee, MD, Vicky Ren, MD, Jill V. Hunter, MBBS, Daniel J. Curry, MD, Fernando Scaglia, MD, Adekunle M. Adesina, MD, PhD, Irfan Ali, MD, Veronica Kinsler, MD, PhD, Lindsay C. Burrage, MD, PhD, and Dana Marafi, MD

Neurol Genet 2019;5:e366. doi:10.1212/NXG.0000000000000366

\section{Abstract}

\section{Objective}

To describe the findings of histopathology and genotyping studies in affected brain tissue from an individual with phacomatosis pigmentovascularis (PPV).

\section{Methods}

A retrospective chart review of a 2-year 10-month-old male with a clinical diagnosis of PPV cesiomarmorata (or type V) was performed. Clinical features, brain imaging and histopathology findings, and genotyping studies in his affected brain tissue are summarized.

\section{Results}

The proband had a clinically severe neurologic phenotype characterized by global developmental delay, generalized hypotonia, and recurrent episodes of cardiac asystole in the setting of status epilepticus. A somatic pathogenic variant in GNA11 (c.547C>T, p.Arg183Cys) was detected in his skin tissue but not in blood (previously published). He underwent an urgent left posterior quadrantectomy for his life-threatening seizures. Histopathology of resected brain tissue showed an increase in leptomeningeal melanocytes and abnormal vasculature, and the exact pathogenic variant in GNA11 (c.547C > T, p.Arg183Cys), previously isolated from his skin tissue but not blood, was detected in his resected brain tissue.

\section{Conclusions}

The finding of this variant in affected skin and brain tissue of our patient with PPV supports a unifying genetic diagnosis of his neurocutaneous features.

\author{
Correspondence \\ Dr. Marafi \\ Dana.marafi@bcm.edu \\ or Dr. Burrage \\ Burrage@bcm.edu
}




\section{Glossary}

AAF = alternate allele read frequency; AED = antiepileptic drug; ES = exome sequencing; GDD = global developmental delay; NCS = neurocutaneous syndrome; PPV = phacomatosis pigmentovascularis; SWS = Sturge-Weber syndrome; VUS = variant of unknown significance.

Phacomatosis pigmentovascularis (PPV) is a group of rare cutaneous syndromes characterized by coexisting widespread vascular and pigmentary lesions of different types. ${ }^{1,2} \mathrm{PPV}$ is currently classified into 3 or 5 types depending on the combination of skin features, but additional systemic features are often observed. $^{2}$ In a study of 24 individuals, clinical and radiologic CNS features were noted in $60 \%$ of PPV cases. ${ }^{3}$ Reported CNS features are similar but not identical to those described in the closely related Sturge-Weber syndrome (SWS) and include seizures, global developmental delay (GDD), intellectual disability, cortical atrophy, asymmetric hemispheres, intracranial hypertension, hydrocephalus, ventriculomegaly, brain calcifications, abnormal EEG, congenital hearing loss, and spina bifida. ${ }^{3-6}$ Because of the rarity of PPV and the multiple subtypes, the neurologic features have not been extensively characterized.

Recently, somatic variants have been identified in several neurocutaneous syndromes (NCSs), including somatic GNAQ variants in SWS. ${ }^{7,8}$ Subsequently, somatic GNA11 or GNAQ variants were identified in multiple skin lesions (pigmentary and vascular) and ocular tissue, but not in blood, in a cohort with PPV and a related cutaneous diagnosis, extensive dermal melanocytosis. ${ }^{1}$

In this report, we describe a life-threatening neurologic phenotype with recurrent status epilepticus and cardiac asystole in a 2-year 10-month-old male with PPV, in which a GNA11 variant was identified in brain and skin but absent in blood. Somatic brain GNA11 pathogenic variant may be identified in the brain of individuals with PPV.

\section{Methods}

We performed a retrospective chart review of an individual with PPV. We summarize his clinical features, brain imaging and histopathology findings, and genotyping studies in his brain tissue.

\section{Standard protocol approvals, registrations, and patient consents}

Permission to publish the case was obtained from the legal guardian of the individual participating in the study. We have also obtained authorization for disclosure of the recognizable photographs that are published in the Journal, in derivative works by the American Academy of Neurology, or on the Journal's website. This work does not include any experiments involving human subjects.

\section{Data availability}

Any unpublished clinical data including clinical pictures, neurophysiology studies, brain images, histopathology slides, and molecular studies can be deidentified and made available upon request.

\section{Clinical report}

The proband is a fraternal twin conceived by in vitro fertilization to Middle Eastern consanguineous parents. Pregnancy was complicated by advanced paternal age, gestational hypertension, and twin-twin transfusion with intrauterine growth restriction in the proband, leading to an urgent cesarean section at 33 weeks. Birth weight was $1.8 \mathrm{~kg}$ (29th percentile, $\mathrm{z}=-0.49$ ). Postnatally, he required respiratory support in the neonatal intensive care unit for 10 days. At age 4 months, he was noted to have poor vision and underwent trabeculectomy for bilateral congenital glaucoma.

At age 15 months, he was hospitalized twice for two separate episodes of cyanosis and apnea after emesis, with the second episode leading to cardiac arrest requiring resuscitation. $\mathrm{He}$ had extensive workup including a 1.5 -T brain MRI that showed cerebral atrophy, hypomyelination, corpus callosum hypoplasia, left lateral ventricle enlargement, and bilateral optic nerve hypoplasia. EEG revealed diffuse background slowing without epileptiform activity. Holter monitoring captured an episode of apnea without cardiac arrhythmias, and echocardiogram showed a questionable mass on the right ventricular wall with normal systolic function and no regurgitation. Renal ultrasound showed small left lower renal pole and interpolar cortical cysts, two right-sided renal arteries, and left renal artery stenosis, for which he underwent balloon dilation. CT of the chest showed atelectasis of the right lung apex and left lung base suggesting recurrent aspirations, and a swallow study demonstrated microaspiration of fluids. Subsequently, the episodes were attributed to gastroesophageal reflux disorder, and he underwent a Nissen fundoplication at age 23 months.

Within 1 month, he had recurrence of the apneic episodes without preceding emesis but with blank stares and progression to right arm and leg stiffening and superimposed tremulousness, unmasking his seizures. Oxcarbazepine was initiated, but he continued to experience prolonged seizures with cardiac asystole requiring resuscitation on 2 additional occasions.

A thorough examination revealed dysmorphic features and skin abnormalities (figure 1). Magnetic resonance angiography, venography, and spectroscopy of the brain were normal. Neurologic examination was notable for marked GDD and generalized hypotonia. At age 2 years, he was nonverbal, 

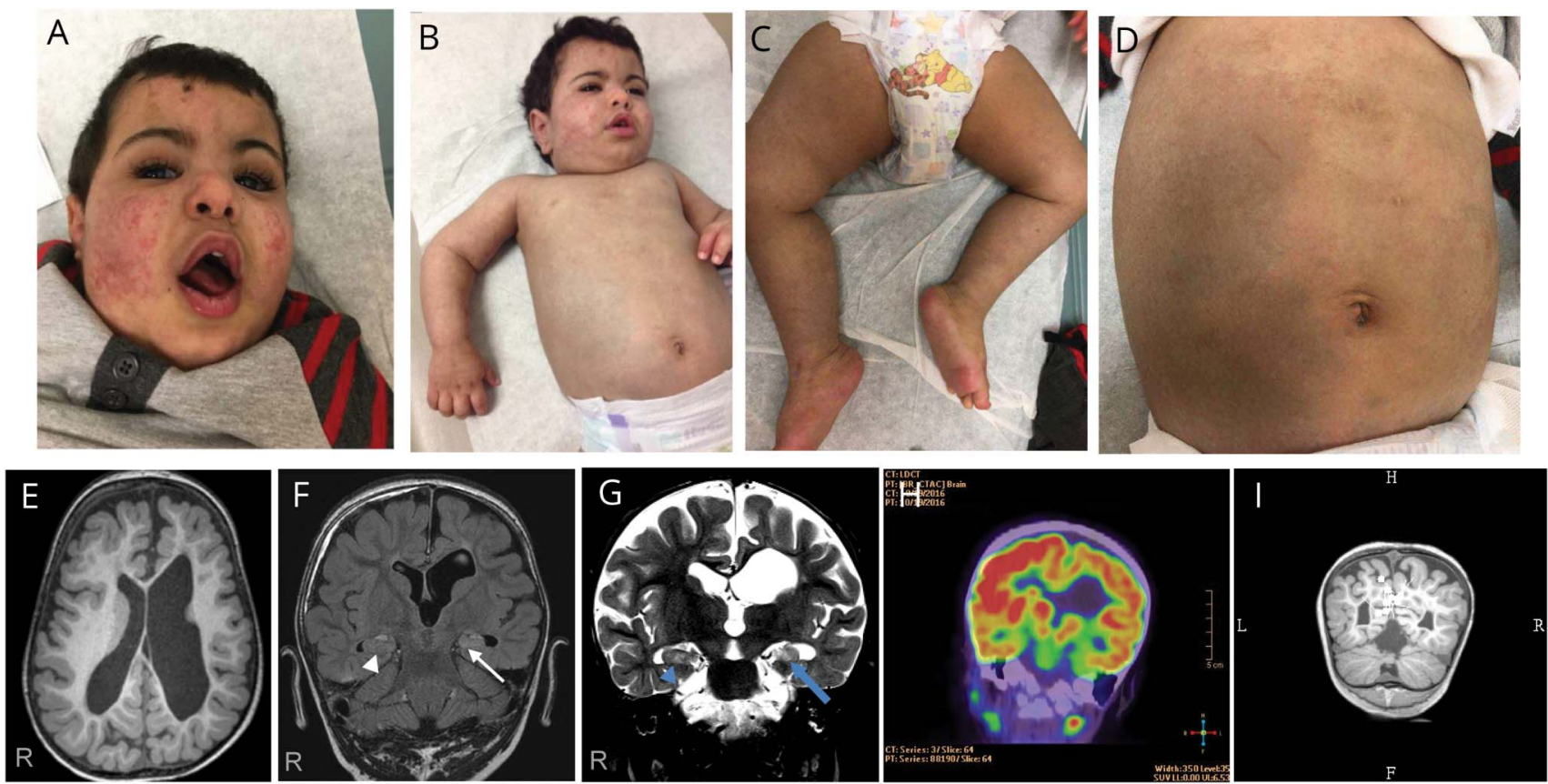

(A) Face and skin findings. Long eyelashes and flat nasal bridge were noted. In addition, he had scleral hyperpigmentation and telangiectasia on both cheeks. (B) Hemihypertrophy of the right arm. (C) Hemihypertrophy of the right leg. (D) Additional skin findings. Cerulean-colored and blanchable, mottled violaceous to erythematous patches on the chest, abdomen, back, and buttocks (not shown). (E) 3T brain MRI (T1 sequence, axial view) shows cerebral atrophy and left lateral ventricle enlargement. (F) 3T brain MRI (FLAIR sequence, coronal view) shows T2 hyperintensity of the left hippocampus (white arrow) and subtle T2 hyperintensity of the right hippocampus (white arrowhead) raising concern for left more than right mesial temporal sclerosis. (G) $3 T$ brain MRI (T2 sequence, coronal view) redemonstrates the T2 hyperintensity of the left hippocampus (blue arrow) and subtle T2 hyperintensity of the right hippocampus (blue arrowhead) raising concern for early left more than right mesial temporal sclerosis. (H) Positron emission tomography elicits a global reduction in Fluorine-18 fluorodeoxyglucose radiotracer uptake over the left hemisphere, particularly left medial temporal lobe. (I) Magnetic encephalography (MEG) performed as part of presurgical epilepsy workup showing a large cluster of MEG sharp waves within the left mesial parieto-occipital sulcus and a small cluster on the right homologous region. FLAIR = fluid-attenuated inversion recovery.

barely sitting unsupported, and had a palmar grasp and reciprocal smile. His vision was poor.

A comprehensive presurgical epilepsy workup (figure 1) was consistent with multifocal epilepsy with evidence for ictal onset from the left posterior quadrant. A 78-hour EEG study captured an hour-long autonomic status epilepticus arising from the left occipital region following withdrawal of his antiepileptic drug (AED). Semiology consisted of sudden-onset tachycardia, with resting heart rate doubling from 78 to 132 beats per minute within seconds. Multifocal epileptiform or paroxysmal fast activity over the bilateral frontocentral, left occipital, and left posterior temporal regions were also observed. Ictal/interictal subtraction single-photon emission computerized tomography was unsuccessful in eliciting an ictal focus. Clobazam was added to his AED regimen.

Trio exome sequencing (ES) (peripheral blood) to evaluate the cause of his seizures and cardiac asystole episodes identified a paternally inherited heterozygous variant of unknown significance (VUS) in DSG2 (c.650C >T, p.Thr217lle), a gene associated with autosomal dominant arrhythmogenic right ventricular dysplasia. Mitochondrial genome sequencing and chromosomal microarray were non-informative. In a previously published study, our patient (patient 8 in table 1 of the previous study), who had been diagnosed with PPV cesiomarmorata (or type V) due to pigmentary lesions on his trunk and vascular lesions on his face, trunk, and limbs, underwent genetic testing. Low-level mosaicism for a pathogenic variant in GNA11 (c.547C > T, p.Arg183Cys) was identified in the DNA extracted from biopsies of his pigmentary and vascular cutaneous lesions (alternate allele read frequency [AAF] of $15.5 \%$ and 9.6\%, respectively), but was not detected in his blood. ${ }^{1}$ Moreover, a reevaluation of his ES data did not identify any alternate allele reads despite $281 \times$ coverage.

Stereotactic depth electrode placement for intracranial EEG monitoring was not performed because of hypotension in the operating room requiring multiple vasopressors. Given his life-threating seizures, a multidisciplinary team agreed that an urgent palliative left posterior quadrantectomy was necessary while his AED doses were increased.

During resection at age 2 years 10 months, brain tissue at the surgical site was discolored (i.e., greenish purple) with abnormal vasculature. Histopathology of the resected medial occipital lobe, superior temporal gyrus, hippocampus, and amygdala tissue revealed mild cortical dysplasia without balloon cells, 
diffuse neuronal heterotopia, reactive gliosis, and increased leptomeningeal melanocytes similar to that observed in the cutaneous lesions (figure 2). Targeted next-generation sequencing of DNA from resected tissue (medial left occipital lobe) identified the exact GNA11 variant detected in skin with AAF of $12.9 \%$ ( $1881 \times$ coverage).

Postoperatively, the patient had immediate and prolonged seizure freedom lasting for 17 months (Engel 1 classification) with interval development of a moderate right-sided weakness. A follow-up EEG showed diffuse background slowing, multifocal epileptiform discharges, and expected continuous left posterior quadrant slowing. Postsurgical brain MRI showed resolution of the right hippocampus hyperintensity (figure 3).

\section{Discussion}

Our patient had PPV with life-threatening recurrent status epilepticus with presumably ictal asystole. Epilepsy and other neurologic features have been described in PPV, although the extent and severity at cohort level are not well documented. ${ }^{3,4,6}$ On the other hand, life-threatening seizures such as apneic seizures are observed in the closely related SWS. ${ }^{5}$ However, our patient only had cutaneous signs of PPV with intracranial involvement, and no evidence for leptomeningeal angiomatosis or facial capillary malformation, typically seen in SWS, was found. In addition, GNA11 somatic variants can cause a range of cutaneous disorders with or without extracutaneous manifestations that are not fully understood. ${ }^{6}$ Thus, our patient may represent the severe end of the spectrum of neurologic features in GNA11-related disorders.

Alternatively, a second diagnosis may explain his neurologic features and asystole episodes. In particular, the contribution of the paternally inherited DSG2 VUS to the phenotype is unclear, although the proband's father is asymptomatic. However, the identification of the somatic GNA11 variant in his cerebral tissue, the immediate and prolonged seizure freedom, and the resolution of his asystole episodes postresection supports a single pathomechanism. This observation would be best confirmed with a longer follow-up and an AED withdrawal challenge.

The interval resolution of the right hippocampal hyperintensity on postoperative brain MRI may be secondary to seizure resolution. However, the increased melanocytes in the leptomeninges are a newly described and important aspect of the neurologic features of PPV, mirroring the coexistence of both pigmentary and vascular lesions on the skin. This finding further supports the hypothesis that the melanocytes are the primary carrier of this somatic mutation and possibly contributes to the severity of neurologic disease in this case of PPV. This is usually only described in a genetically distinct pigmentary mosaic condition multiple congenital melanocytic nevi, ${ }^{9,10}$ where it leads to seizures and GDD. No evidence of intraparenchymal melanosis was seen on histopathology of the left mesial temporal specimen.

Somatic variants in GNA11 have been previously isolated from skin but not brain parenchyma in PPV. ${ }^{1}$ There is growing evidence for brain somatic variants in other NCSs and nonlesional and lesional epilepsies including a spectrum of epileptic neurodevelopmental malformations ranging from isolated focal cortical dysplasia to bilateral brain overgrowth. ${ }^{7,10-12}$ The presence of the GNA11 variant in only brain and skin tissue is consistent with an early somatic mutation. ${ }^{12}$ Detection of such low-level mosaicism requires coupling advanced and sensitive sequencing technology with accurate tissue selection. ${ }^{12}$

Our case expands the clinical and molecular spectrum of PPV and GNA11-related disorders. However, our study has a few limitations because it represents a single case report with a short follow-up period. An in-depth understanding of the neurologic features and confirmation of this molecular finding will require a larger PPV cohort.

\section{Author contributions}

S.C. McGriff, J.M. Sliepka, and L.Z. Rossetti: acquisition of data and drafting of the manuscript. P. Bizargity: acquisition

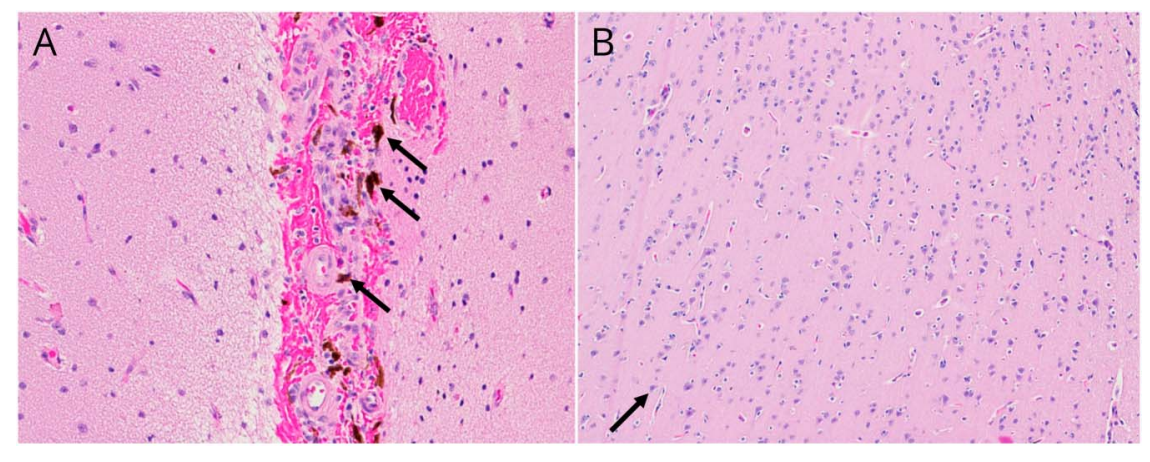

(A) Diffuse leptomeningeal melanosis (black arrows). (B) Accentuation of columnar architecture (black arrow) consistent with cortical dysplasia. 

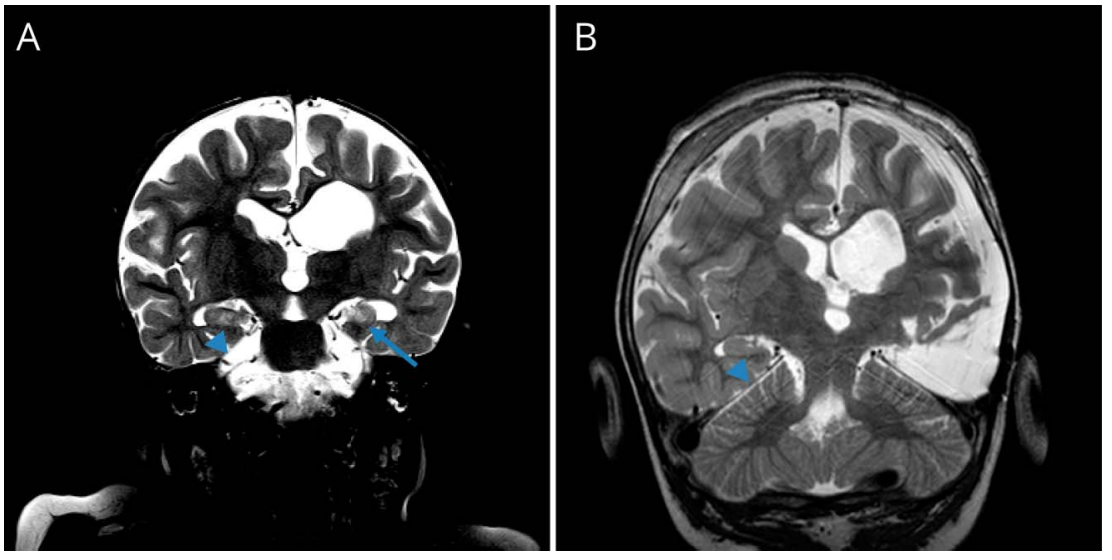

(A) Presurgical MRI (FLAIR sequence, coronal view) showing the T2 hyperintensity of the left hippocampus (blue arrow) and subtle T2 hyperintensity of the right hippocampus (blue arrowhead). (B) Postsurgical MRI (FLAIR sequence, coronal view) showing a surgical cavity on the left temporal region and resolution of the T2 hyperintensity of the right hippocampus (blue arrowhead). FLAIR = fluid-attenuated inversion recovery.

and interpretation of data. H. Streff: acquisition of data. Y.-S. Lee and H. Dai: acquisition and interpretation of data. S. Polubothu: acquisition and interpretation of initial data. V. Ren and G. Lee: acquisition of data. J.V. Hunter: acquisition and interpretation of data. D.J. Curry and F. Scaglia: acquisition of data. A.M. Adesina: acquisition and interpretation of data. I. Ali: acquisition of data. V. Kinsler: acquisition and interpretation of initial data and critical revision of the manuscript for intellectual content. L.C. Burrage: acquisition and interpretation of data and critical revision of the manuscript for intellectual content. D. Marafi: acquisition and interpretation of data, drafting the manuscript, and critical revision of the manuscript for intellectual content.

\section{Acknowledgment}

The authors acknowledge the patient and his family for their participation in this study.

\section{Study funding}

D. Marafi was supported by the NIH National Institute of General Medicine Sciences (NIGMS) T32 GM007526-41. V. Kinsler is funded by the Wellcome Trust, award number WT104076MA.

\section{Disclosure}

Disclosures available: Neurology.org/NG.

\section{Publication history}

Received by Neurology: Genetics May 12, 2019. Accepted in final form September 4, 2019.

\section{References}

1. Thomas AC, Zeng Z, Riviere JB, et al. Mosaic activating mutations in GNA11 and GNAQ are associated with phakomatosis pigmentovascularis and extensive dermal melanocytosis. J Invest Dermatol 2016;136:770-778.

2. Happle R. Phacomatosis pigmentovascularis revisited and reclassified. Arch Dermatol 2005;141:385-388.

3. Vidaurri-de la Cruz H, Tamayo-Sanchez L, Duran-McKinster C, Orozco-Covarrubias Mde L, Ruiz-Maldonado R. Phakomatosis pigmentovascularis II A and II B: clinical findings in 24 patients. J Dermatol 2003;30:381-388.

4. Fernandez-Guarino M, Boixeda P, de Las Heras E, Aboin S, Garcia-Millan C, Olasolo PJ. Phakomatosis pigmentovascularis: clinical findings in 15 patients and review of the literature. J Am Acad Dermatol 2008;58:88-93.

5. Pinto AL, Chen L, Friedman R, et al. Sturge-Weber syndrome: brain magnetic resonance imaging and neuropathology findings. Pediatr Neurol 2016;58:25-30.

6. Kumar A, Zastrow DB, Kravets EJ, et al. Extracutaneous manifestations in phacomatosis cesioflammea and cesiomarmorata: case series and literature review. Am J Med Genet A 2019;179:966-977.

7. Shirley MD, Tang H, Gallione CJ, et al. Sturge-Weber syndrome and port-wine stains caused by somatic mutation in GNAQ. N Engl J Med 2013;368:1971-1979.

8. Ruggieri M, Pratico AD. Mosaic neurocutaneous disorders and their causes. Semin Pediatr Neurol 2015;22:207-233.

9. Kinsler VA, Paine SM, Anderson GW, et al. Neuropathology of neurocutaneous melanosis: histological foci of melanotic neurones and glia may be undetectable on MRI. Acta Neuropathol 2012;123:453-456.

10. Kinsler VA, Thomas AC, Ishida M, et al. Multiple congenital melanocytic nevi and neurocutaneous melanosis are caused by postzygotic mutations in codon 61 of NRAS. J Invest Dermatol 2013;133:2229-2236.

11. D'Gama AM, Woodworth MB, Hossain AA, et al. Somatic mutations activating the mTOR pathway in dorsal telencephalic progenitors cause a continuum of cortical dysplasias. Cell Rep 2017;21:3754-3766.

12. D'Gama AM, Walsh CA. Somatic mosaicism and neurodevelopmental disease. Nat Neurosci 2018;21:1504-1514. 


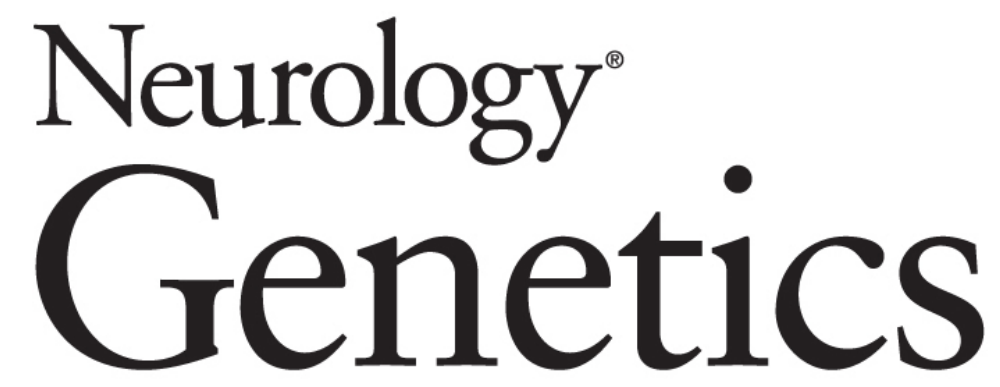

GNA11 brain somatic pathogenic variant in an individual with phacomatosis pigmentovascularis

Joseph M. Sliepka, Sarah C. McGriff, Linda Z. Rossetti, et al.

Neurol Genet 2019;5;

DOI 10.1212/NXG.0000000000000366

This information is current as of October 30, 2019

Neurol Genet is an official journal of the American Academy of Neurology. Published since April 2015, it is an open-access, online-only, continuous publication journal. Copyright Copyright ( 2019 The Author(s). Published by Wolters Kluwer Health, Inc. on behalf of the American Academy of Neurology.. All rights reserved. Online ISSN: 2376-7839.

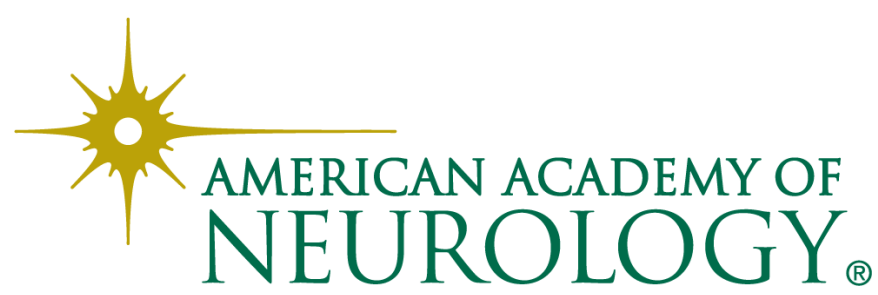




\section{Updated Information \& Services}

References

Subspecialty Collections

Permissions \& Licensing

Reprints including high resolution figures, can be found at:

http://ng.neurology.org/content/5/6/e366.full.html

This article cites 12 articles, 0 of which you can access for free at: http://ng.neurology.org/content/5/6/e366.full.html\#\#ref-list-1

This article, along with others on similar topics, appears in the following collection(s):

All Clinical Neurology

http://ng.neurology.org//cgi/collection/all_clinical_neurology

All Epilepsy/Seizures

http://ng.neurology.org//cgi/collection/all_epilepsy_seizures

\section{All Genetics}

http://ng.neurology.org//cgi/collection/all_genetics

Developmental disorders

http://ng.neurology.org//cgi/collection/developmental_disorders

Other neurocutaneous disorders

http://ng.neurology.org//cgi/collection/other_neurocutaneous_disorders

Information about reproducing this article in parts (figures,tables) or in its entirety can be found online at:

http://ng.neurology.org/misc/about.xhtml\#permissions

Information about ordering reprints can be found online:

http://ng.neurology.org/misc/addir.xhtml\#reprintsus

Neurol Genet is an official journal of the American Academy of Neurology. Published since April 2015, it is an open-access, online-only, continuous publication journal. Copyright Copyright ( 2019 The Author(s). Published by Wolters Kluwer Health, Inc. on behalf of the American Academy of Neurology.. All rights reserved. Online ISSN: 2376-7839.

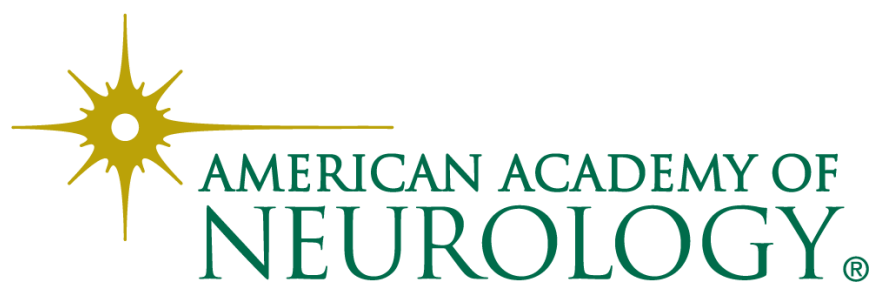

